\title{
SANEAMENTO BÁSICO NO MUNICÍPIO DE INDIANA-SP
}

Angelo José Garcia Borges ${ }^{1}$, Juliane Sanches Vicente' ${ }^{1}$, Mayara Pissutti Albano², Yeda Ruiz Maria²

1 Discentes do curso de Arquitetura e Urbanismo da Universidade do Oeste Paulista - UNOESTE. ${ }^{2}$ Docentes dos cursos de arquitetura e urbanismo, engenharia ambiental e sanitária, design de interior e engenharia de produção da Universidade do Oeste Paulista - UNOESTE. E-mail: angelogborges@hotmail.com

\section{RESUMO}

Com o crescimento acelerado da população mundial, o consumo excessivo, o consequente aumento na produção de resíduos e o descarte irresponsável desses resíduos no meio ambiente, têm levado a uma preocupação mais abrangente, a escassez dos recursos naturais e degradação do meio ambiente. Assim, resultando uma preocupação com o saneamento devido aos problemas com transmissão de doenças. No saneamento básico há um baixo investimento financeiro. Há atuações para melhoria da qualidade ambiental e de vida da população, porém, os municípios de pequeno porte apresentam dificuldades para aproveitar ao máximo essas ações. O presente artigo trata-se de uma visão geral sobre o saneamento básico da cidade de Indiana, estado de São Paulo. Foram levantadas informações através da prefeitura municipal de Indiana, jornal O Imparcial e CETESB sobre os serviços de abastecimento de água, tratamento de esgoto sanitário e coleta de lixo. A pesquisa foi efetuada por meio de eletrônico e bibliotecas.

Palavra-chave: Abastecimento de água, tratamento de esgoto, coleta de lixo, planejamento urbano.

\section{INTRODUÇÃO}

Segundo a Organização Mundial de Saúde - OMS, saneamento é o controle de todos os fatores do meio físico do homem, que exercem ou podem exercer efeitos nocivos sobre o bem estar físico, mental e social. De outra forma, pode-se dizer que saneamento caracteriza o conjunto de ações socioeconômicas que tem por objetivo alcançar salubridade ambiental. Esta entendido como estado de estado de saúde normal em que vive a população urbana e rural, tanto no que se refere a sua capacidade de inibir, prevenir ou impedir a ocorrência de endemias ou epidemias veiculadas pelo meio ambientes, como no tocante ao seu potencial de promover o aperfeiçoamento de condições do clima e/ou ambiente favoráveis ao pleno gozo de saúde e bemestar (GUIMARÃES, CARVALHO; SILVA, 2007).

A utilização do saneamento como instrumento de promoção da saúde pressupõe a superação dos entraves tecnológicos, políticos e gerenciais que têm dificultado a extensão dos benefícios aos residentes em áreas rurais, municípios e localidades de pequeno porte (GUIMARÃES, CARVALHO; SILVA, 2007). 
Saneamento significa higiene e limpeza (CAVINATTO, 1992). Dentre as principais atividades de saneamento estão à coleta e o tratamento de resíduos das atividades humanas, tanto sólidos quanto líquidos (lixo e esgoto), prevenir a poluição das águas de rios, mares e outros mananciais, garantir a qualidade da água utilizada pelas populações para consumo, bem como seu fornecimento de qualidade, além do controle de vetores. Incluem-se ainda no campo de atuação do saneamento a drenagem das águas das chuvas, prevenção de enchentes e cuidados com as águas subterrâneas (RIBEIRO; ROOKE, 2010).

O saneamento básico, portanto, é fundamental na prevenção de doenças. Além disso, a conservação da limpeza dos ambientes, evitando resíduos sólidos em locais inadequados, por exemplo, também evita a proliferação de vetores de doenças como ratos e insetos que são responsáveis pela disseminação de algumas moléstias (CAVINATTO, 1992).

Segundo Guimarães, Carvalho e Silva (2007), o saneamento abrange os seguintes serviços:

- $\quad$ Abastecimento de água às populações, com a qualidade compatível com a proteção de sua saúde e em quantidade suficiente para a garantia de condições básicas de conforto;

- $\quad$ Coleta, tratamento e disposição ambientalmente adequada e sanitariamente segura de águas residuárias (esgotos sanitários, resíduos líquidos industriais e agrícolas);

- Acondicionamento, coleta, transporte e destino final dos resíduos sólidos (incluindo os rejeitos provenientes das atividades doméstica, comercial e de serviços, industrial e pública);

- $\quad$ Coleta de águas pluviais e controle de poças e inundações;

- $\quad$ Controle de vetores de doenças transmissíveis (insetos, roedores, moluscos, etc.);

- $\quad$ Saneamento dos alimentos;

- $\quad$ Saneamento dos meios de transportes;

- $\quad$ Saneamento e planejamento territorial;

- Saneamento da habitação, dos locais de trabalho, de educação, de recreação e dos hospitais;

- $\quad$ Controle da poluição ambiental - água, ar, solo, acústica e visual.

Assim sendo este artigo busca analisar e demonstrar como é realizado o abastecimento de água, tratamento de esgoto e coleta de lixo em Indiana, cidade do interior do Estado de São Paulo. E mostrar a importância de um planejamento urbano ambiental, sendo este um ponto de partida para a valorização e conservação do meio ambiente em cada cidade.

Para coleta do material, foram realizadas duas visitas à cidade de Indiana - SP com conversas informais junto à Prefeitura Municipal e moradores locais, referentes à coleta de lixo e 
tratamento de esgoto. Houve pesquisa no site oficial da prefeitura municipal de Indiana, na Companhia Ambiental do Estado de São Paulo - CETESB, regional de Presidente Prudente-SP, e leitura de bibliografia especifica sobre saneamento básico, sua conceituação, importância e aplicação.

\section{INDIANA-SP E O SANEAMENTO BÁSICO}

De acordo com estudos, sobre saneamento básico, realizados pelo governo brasileiro, o saneamento básico no Brasil apresenta inúmeras falhas, especialmente nos municípios de pequeno porte, que a população estimada é inferior a 30.000 habitantes (CARDOSO et al., 2006).

No saneamento básico há um baixo investimento financeiro. Há atuações para melhoria da qualidade ambiental e de vida da população, porém, os municípios de pequeno porte apresentam dificuldades para aproveitar ao máximo essas ações.

De acordo com dados do IBGE (2013), o município possui uma população total de 4.803 habitantes, em uma área territorial de 17,6 quilômetros quadrados. A extensão da área da cidade é bem maior que a área ocupada pela cidade.

Segundo dados disponibilizados pelo departamento de água e esgoto da prefeitura, o Departamento de Água e Esgoto - D.A.E (2013), Indiana possui um consumo de água de $960 \mathrm{~m}^{3} /$ dia, há 1.606 ligações, que correspondem a um percentual de cobertura de aproximadamente $95 \%$ da população. A distribuição é feita por uma caixa d'água, que está localizada na Rua Capitão Witaker. Essa caixa d'água é abastecida por quatro poços artesianos de profundidade variável: dois de 70 metros, um de 60 metros e um de 180 metros, que foram ampliados conforme demanda e estão sendo usados desde o início da cidade. Existem poços artesianos particulares na área rural, mas sem registro de localização, profundidade e quantidade (D.A.E., 2013).

O Esgoto é tratado pelo Sistema Australiano ${ }^{1}$, iniciado em meados de 2006 , constituído de duas lagoas de estabilização (uma aeróbia e uma anaeróbia). Sua profundidade é de dois metros, com volume de $13.180 \mathrm{~m}^{3}$ e o tempo de detenção é de 13,73 dias. Essas duas lagoas de tratamento estão localizadas na estrada municipal Ind 040, no sítio São Bento, no bairro Novo Destino, com área do terreno de $24.200 \mathrm{~m}^{2}$, sendo ocupados $12.160 \mathrm{~m}^{2}$. As lagoas de tratamento recebem o esgoto através de duas bacias de drenagem compostas de duas estações elevatórias que convergem a um ponto de lançamento (Córrego do Acampamento ou Novo Destino). O solo é

\footnotetext{
${ }^{1}$ Sistema Australiano de tratamento de esgoto é constituído por lagoas anaeróbias seguidas por lagoas facultativas (FEC, 2013).
} 
arenoso, com profundidade do lençol freático acima de 3,50 metros. Este tratamento tem eficiência de 80\% (CETESB, 2013).

O efluente final de tratamento de esgoto deve atender aos padrões da emissão de quantidade definidos nos artigos 11 e 18, do Regulamento da Lei Estadual 997/76, aprovado pela Resolução CONAMA n20 de 18/06/1086, no qual estabelece o limite de 5mg/L da Demanda Bioquímica de Oxigênio - DBO (CETESB, 2013).

Este tratamento atende a uma população final de 5.000 habitantes, com uma extensão de rede de 6.138 metros. Existem 1.410 ligações que correspondem a um percentual de cobertura de $82 \%$. A quantidade de esgoto tratado é $960 \mathrm{~m}^{3} / \mathrm{dia}$, valor correspondente à quantidade de água consumida diariamente, classificado como classe dois na Resolução CONAMA 357 (CETESB, 2013) (Figura 1).

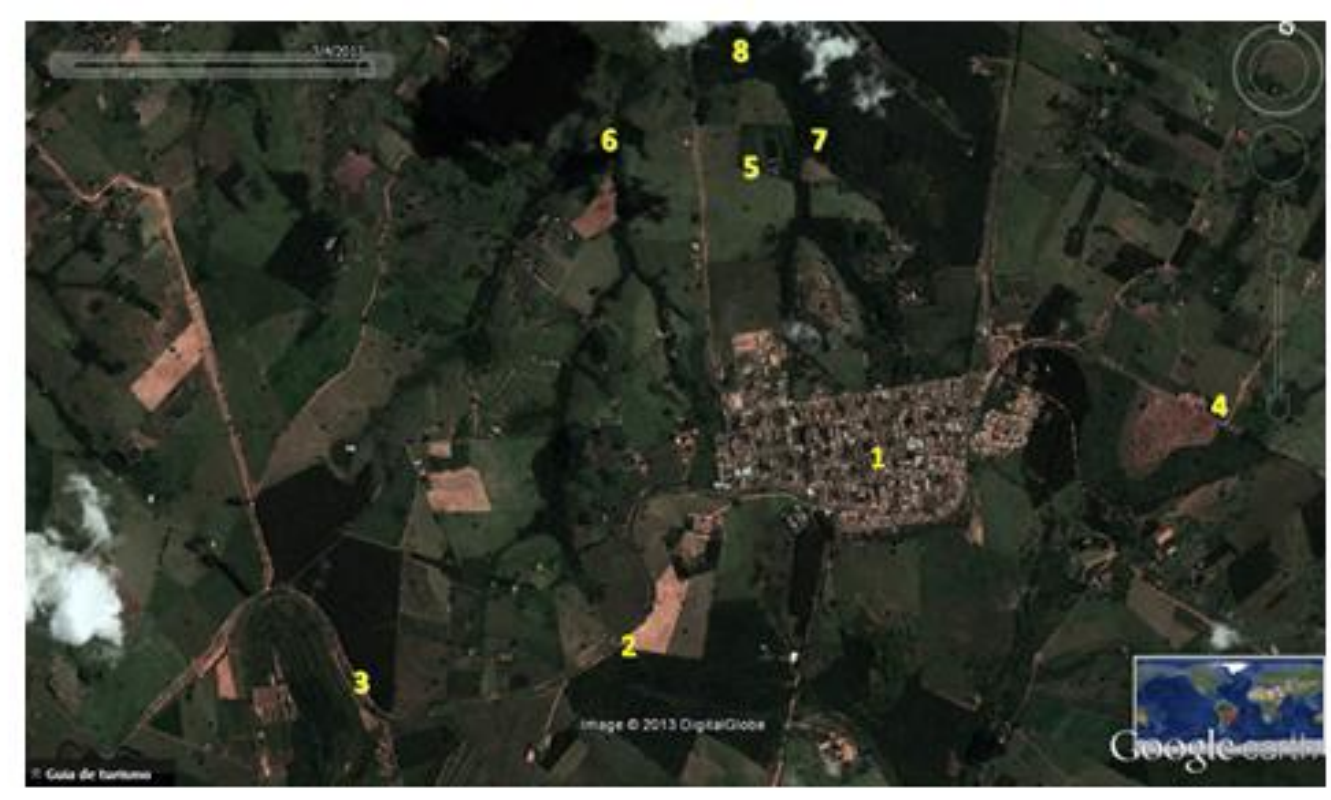

\section{1: Cidade de Indiana 3: Aterro Sanitário 2 (em uso) 5: Lagoa de Tratamento (Sistema Australiano) 7: Córrego do Liberal}

2: Área Recuperada (Local aterro sanitário antigo) 4: Aterro Sanitário 3 (em uso)

6: Córrego do Acampamento

8: Cachoeira do Liberal (local de encontro dos córregos)

Figura 1. Aterros Sanitários

Fonte: Google Mapas, 2013. Org.: os autores

De acordo com o artigo de lury Greghi no Jornal O Imparcial, de 11 de junho de 2013, a qualidade dos aterros sanitários na região de Presidente Prudente melhorou entre 2011 e 2012, segundo CETESB (Companhia Ambiental do Estado de São Paulo). Em uma escala que varia até 10, 
os depósitos regionais atingiram média de 7,44, ante 7,37 do cálculo anterior. Apesar do avanço, a região permanece aquém do índice estadual, que é de 8,3. A CETESB avalia como inadequadas as áreas cujo índice seja inferior a sete. Os dados estão contidos no Inventário Estadual de Resíduos Sólidos Urbanos 2012, divulgado pela companhia ambiental. O relatório é resultado de inspeções periódicas feitas em todos os aterros do Estado em pelo menos três visitas por ano em cada local, onde é verificado se o lixo está sendo depositado e aterrado de maneira correta.

Podemos observar na figura 5 as cidades inadequadas (índice abaixo de sete e que a cidade de Indiana encontra-se nesse contexto.

\begin{tabular}{|c|c|c|c|}
\hline \multirow[t]{2}{*}{ MUNICÍPIOS } & Lixo ( $t /$ dia) & "Qualidade" & "Qualidade" \\
\hline & & \multicolumn{2}{|c|}{ do aterro $2011^{\prime \prime}$ do aterro $2012^{\prime \prime}$} \\
\hline Indiana & 1,6 & 7 & 6,2 \\
\hline Mirante do Paranapanema & 4,05 & 6,8 & 6,7 \\
\hline Osvaldo Cruz & 11,18 & 5,2 & 4,2 \\
\hline Paraguaçu Paulista & 15,4 & 5,1 & 4,8 \\
\hline Pirapozinho & 9,53 & 5,3 & 4,2 \\
\hline Presidente Epitácio & 15,53 & 5,9 & 2,9 \\
\hline Presidente Prudente & 123,66 & 3,8 & 2,7 \\
\hline Presidente Venceslau & 14,54 & 6,2 & 6,1 \\
\hline Sandovalina & 1 & 6,9 & 6,9 \\
\hline Santa Mercedes & 0,9 & 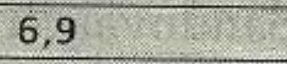 & 6,7 \\
\hline Taciba & 1,97 & 7,2 & 6,7 \\
\hline 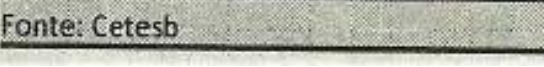 & & 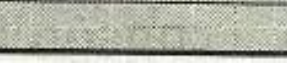 & 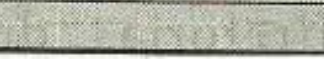 \\
\hline
\end{tabular}

Figura 2. Cidades inadequadas quanto a qualidade dos aterros Fonte: Jornal O Imparcial, 11/06/2013.

A quantidade de lixo produzido e coletado diariamente é de aproximadamente seis toneladas/dia. A coleta de lixo é feita pela prefeitura municipal, através de caminhões. Existem três aterros sanitários para depósito de lixo, onde um já está saturado (permitindo crescimento de vegetação espontânea) e dois em uso. Também há coleta de entulhos de construção e galhos de árvores que são lançados em valas diversas, servindo como aterro e a parte verde serve como produção de húmus (PREFEITURA MUNICIPAL DE INDIANA, 2013).

Não existe coleta seletiva apesar de existirem cestos de lixos apropriados na praça da cidade. 


\section{CONSIDERAÇÕES FINAIS}

Devido à falta de planejamento urbano ambiental ocorre uma degradação nas cidades, na qual afeta diretamente a qualidade de vida das populações com prejudiciais efeitos sobre o uso e ocupação dos solos, qualidade do ar, poluição sonora, redução das áreas verdes, lixo, degradação dos valores éticos, violência, abandono de crianças, desigualdades sociais e exclusão. Mas a falta de saneamento básico seria uma das formas de preservação ao alcance das políticas ambientais, tanto em prevenções de doenças quanto na preservação do meio ambiente.

Com base nas informações obtidas sobre o tratamento de água, esgoto e coleta de lixo na cidade de Indiana, observa-se que apesar da cidade ser pequena e com poucos recursos é bem assessorada. As taxas de percentual de cobertura de água e esgoto é quase $100 \%$, taxa que deverá ser atingida nos próximos anos até que os investimentos em infraestrutura se concretizem e seja alcançada a cobertura total.

Ainda há deficiência de atendimento, tanto que existem fossas nos bairros mais antigos, sem a presença de rede pública, e boa parte da população é rural.

A cidade de Indiana é limpa, o lixo é recolhido todos os dias, os aterros sanitários são considerados distantes da cidade nos dias de hoje em função de sua pequena extensão, porém, de acordo com a CETESB, a qualidade dos aterros é considerada inadequada e também se observa uma falta de orientação dos mesmos em relação ao fluxo dos ventos da região conforme podemos ver na figura 1 , o que pode eventualmente acarretar mau cheiro na cidade, trazido pelos ventos, indicando uma falha no planejamento urbano ambiental.

\section{REFERÊNCIAS}

CARDOSO, F. K. et al. Proposta de integração das ações de saneamento ambiental por meio do planejamento estratégico em um município de pequeno porte do estado de minas gerais - Brasil. In: congreso interamericano de ingeniería sanitaria y ambiental, 30., 2006, Punta del Este. Anais... Punta del Este - Uruguay, p. 1-8, 2006, p. 1-8.

CAVINATTO, V. M. Saneamento básico: fonte de saúde e bem-estar. São Paulo: Moderna, 1992. CETESB - Companhia Ambiental do Estado de São Paulo. Presidente Prudente. Atendimento ao Cidadão em 06 mai. 2013.

FEC - Faculdade de Engenharia Civil, Arquitetura e Urbanismo. Disponível em: <http://www.fec.unicamp.br/ bdta/esgoto/lagoas.htm|\#sistlaganafac >. Acesso em: 06 ago. 2013. GREGHI, I. Qualidade dos aterros sobe, mas está aquém do Estado. Jornal O Imparcial, Presidente Prudente, Caderno b, Cidades, 11 jun 2013. 
GUIMARÃES, A. J. A.; CARVALHO, D. F.; SILVA, L. D. B. Saneamento básico, ago. 2007. Disponível em: <http://www.ebah.com.br/content/ABAAABwH8AG/capitulo1-saneamento-basico\#>. Acesso em: 05 jun. 2013.

INSTITUTO Brasileiro de Geografia e Estatística. Cidades: Indiana, SP. Disponível em: <http://www.ibge.gov.br/cidadesat/painel/painel.php?codmun=352060>. Acesso em: 04 mai. 2013.

PREFEITURA Municipal de Indiana. A cidade: história da cidade. Disponível em: <http://www.indiana.sp.gov.br/cidade.php?codid=1>. Acesso em 05 mai. 2013.

RIBEIRO, J. W.; ROOKE, J. M. S. Saneamento básico e sua relação com o meio ambiente e a saúde pública. Trabalho de Conclusão de Curso (Especialização em Análise Ambiental) - Faculdade de Engenharia, Universidade Federal de Juiz de Fora, Juiz de Fora, 2010.

von SPERLING, M. Princípios do tratamento biológico de águas residuárias: lagoas de estabilização. Minas Gerais: ABES, v. 3, 1996. 